\title{
Synthesis and Spectroscopic Analysis of Au-Ag Alloy Nanoparticles with Different Composition of Au and Ag
}

\author{
Latif-ur-Rahman ${ }^{1, *}$, Anwar-ul-Haq Ali Shah ${ }^{1}$, Afzal Shah ${ }^{2}$, Syed Muhammad Salman ${ }^{3}$, Abdul Khaliq \\ Jan 4 \\ 1 Institute of Chemical Sciences, University of Peshawar, Peshawar 25120, Khyber Pakhtunkhwa, Pakistan; \\ latif.wardag@uop.edu.pk (L.R.), anwarulhaqalishah@uop.edu.pk (A.H.A.S.); \\ 2 Department of Chemistry, Quaid-i-Azam University, Islamabad 45320, Pakistan; afzals_qau@ yahoo.com (A.S.); \\ 3 Department of Chemistry, Islamia College Peshawar, Peshawar-25120, Pakistan; salman@icp.edu.pk (S.M.S.); \\ 4 Department of Chemistry, Shaheed Benazir Bhutto University, Upper Dir 18050, Pakistan; abdukhaliq@gmail.com \\ (A.K.J.); \\ * Correspondence: latif.wardag@uop.edu.pk;
}

Scopus Author ID 39462006200

Received: 1.03.2021; Revised: 2.04.2021; Accepted: 5.04.2021; Published: 20.04.2021

Abstract: Au-Ag bimetallic alloy nanoparticles, having an average size from 35 to $25 \mathrm{~nm}$, were successfully synthesized (using chemical reduction process) from $\mathrm{AuCl}_{3}$ and $\mathrm{AgNO}_{3}$. Ethylene glycol was used as a solvent and polyaniline (PANI) as a capping agent. Au-Ag alloy nanoparticles, with different proportions among $\mathrm{Au}$ and $\mathrm{Ag}$, were synthesized and characterized by various spectroscopic techniques. The steady-state fluorescence spectroscopy, X-ray diffraction (XRD), and Scanning Electron Microscopy (SEM) data revealed the formation of alloy nanoparticles of various compositions, which agrees with the absorption data obtained by UV-Visible spectroscopy. Ag was found to be acting as a quencher for emission radiations, as evidenced by fluorescence spectroscopy. XRD data pointed out the crystalline structure of alloy nanoparticles. Variation in Au and Ag's atomic composition in Au$\mathrm{Ag}$ was confirmed by energy dispersive spectroscopy (EDS). Scanning Electron Microscopy (SEM) was applied to study the morphology of the bimetallic alloy nanoparticles. Interestingly, the size of nanoparticles decreases with a decrease in Au's composition in Au-Ag alloy nanoparticles. Maximum values of molar absorptivity were recorded by Au-Ag alloy nanoparticles with ratio 1:3, which indicates that at ratio 1:3 of $\mathrm{Au}$ and $\mathrm{Ag}$ in $\mathrm{Au}-\mathrm{Ag}$ alloy nanoparticles, the size of the nanoparticles is minimum with maximum surface area.

Keywords: Au-Ag alloy; bimetallic nanoparticles; polyaniline; crystalline nanoparticles; quencher.

(C) 2021 by the authors. This article is an open-access article distributed under the terms and conditions of the Creative Commons Attribution (CC BY) license (https://creativecommons.org/licenses/by/4.0/).

\section{Introduction}

Nanoparticles have a vast range of applications in many spheres of life. These extraordinary properties were owing to their size, shape, and structure. The geometrical, statistical, and quantum impacts change with the reducing size of the nanoparticles. Reducing the size from macro to micro-level, no change is viable; however, nano range is effective [1]. Nanoparticles, either in monometallic or in bimetallic form, show valuable properties, which help us in different research fields. They have accompanied their precedence in agriculture by making the plants' quality better. Due to the underlying reasons, their importance is increasing day by day [2]. 
Among the nanoparticles, bimetallic nanoparticles are of the utmost importance. Alloying of different metals at a nanoscale gives birth to new species with important physicochemical properties and can be used in different fields for specific applications [3]. As bimetallic nanoparticles' properties vary with size, composition, and morphology, they can optimize the behaviors of materials for so many applications in electrochemical sensor development. Researchers have focused on controlling their size and structure [4]. Bimetallic nanoparticles may have different structures like the random cluster in the cluster, core-shell, and alloy structure [5]. Metals are having the same atomic size from a random alloy, while those with unequal atomic sizes give rise to intermetallic alloy [6].

Bimetallic alloy nanoparticles have a vast application due to their degree of freedom as compared to monometallic nanoparticles, but we are still unable to cope with changes in internal structure and chemical order of those which have a size less than $5 \mathrm{~nm}$ [7]. Variation in bimetallic alloy nanoparticles' surface physiochemical properties by sensing other species in their environment can help us detect harmful and carcinogenic substances such as Volatile Organic Compounds [8]. For example, Au-Ag Bimetallic nanoparticles can be used to detect polycyclic aromatic hydrocarbons (PAHs); hence $\mathrm{Au}-\mathrm{Ag}$ nanoparticles-based sensors can be developed to detect one of the harmful and environmental toxins PAHs, called pyrene [9]. Similarly, alloying Ag nanoparticles with $\mathrm{Cu}$ improves seed germinations and some medicinal plants' hormonal activities [10]. A sensor made up of $\mathrm{Ag}-\mathrm{Cu}$ along with a polymer called poly ethyl imine has been developed, which can be used for the detection of 2-butanone from the exalted mouth breath during exhalation of the infected human beings, and hence, gastric and lung cancer can be investigated at the early stages [11].

It ultimately spurs its properties, i.e., electrochemical and biochemical sensors development. The preparation could be done through various methods; however, among all methods, a chemical reduction is the simplest and less time-consuming [12]. Among the nanoparticles, Au-Ag bimetallic alloy nanoparticles have so many applications in developing electrochemical sensors, biosensors, and accelerating some important medicinal plants' seed germination. Ag has the highest electrical properties, and its flakes have various applications [13]. However, the limiting factor is Ag ions' electromigration in the Ag-filled adhesives when there are an electrical bias and humidity. Au is used as its bimetallic partner to cope with Ag's problem due to its low electrical migration, high electrical conductivity, and high compatibility [14]. Due to Au and Ag films' melting point's higher conductivity, the alloy of its bimetallic nanoparticles ranges in applications from potential, optical, macroscopic to liability, which induces system failure and reduction of electromigration [15].

Eruca Sativa, which is economically and commercially important due to its nutritional and medicinal importance, has improved plant tissue culture [16]. In-plant tissue culture, nanoparticles are used, which affect the synthesis and production of secondary metabolites. In such plants, nanoparticles enter the cell wall and hence change the cell's internal environment, i.e., reactive oxygen species and hydroxyl radicals are formed. As a result, the cell wall's permeability is disturbed, and stress is affected on the cell wall due to nanoparticles of different sizes, shapes, and properties [17]. As a result of such stress, secondary metabolites are formed in plant cells, which finally paves the way for nanoparticles to influence the plant's growth rate [18].

The effect of nanoparticles is direct on humans, plants, and bacteria. Scientists have struggled to know about the effects of different nanoparticles, including the monometallic and bimetallic alloy nanoparticles, on plants' seed germination [19]. Monometallic nanoparticles 
influence seed germination due to their toxicity. This toxic effect of monometallic nanoparticles is due to the production of reactive oxygen species and hydroxyl radicals inside the cell when nanoparticles get into it through the cell wall [20]. In one report, it has been described that effect of monometallic nanoparticles on seed germination can be positive or negative because when seeds of spinach were soaked in nanoparticles suspension, it promoted its growth at first, but later on its growth was abated, so the effects on seed germination can be found out by knowing its toxicity which can be determined by studying the size, shape, and properties of nanoparticles [20].

Different electrochemical sensors are developed based on bimetallic alloys, which help us determine the most important and carcinogenic substances in very trace amounts. By incorporating $\mathrm{Ag}$ to $\mathrm{Au}$ and making their bimetallic alloys, the sensing activity of the primer is improved up to a high extent [21].

\section{Materials and Methods}

$\mathrm{Au}-\mathrm{Ag}$ alloy nanoparticles were synthesized by a chemical reduction process [22]. In the chemical reduction process, ethylene glycol was used as a polar solvent that can act as a reducing agent for $\mathrm{Ag}^{+}$and $\mathrm{Au}^{3+}$ ions, while Polyaniline (PANI) $\mathrm{Mw}=15000 \mathrm{~g}$ was used as a surfactant that has additional benefit to prevent the self-aggregation of ions and stabilize the nanoparticles. The detail of the chemicals used, along with their physical properties are listed in Table 1.

Table 1. List of chemicals, their physical properties, and purities.

\begin{tabular}{l|l|c|c|c|c} 
S. No & Compound & MW/gram & $\begin{array}{c}\text { Solubility in } \\
\text { Ethylene glycol }\end{array}$ & $\begin{array}{c}\text { Purity } \\
\mathbf{\%})\end{array}$ & Provider \\
\hline 1 & Silver nitrate & 169.87 & Soluble & 99.95 & BDH \\
\hline 2 & Hydrogen gold chloride & 303.47 & Soluble & 99.99 & BDH \\
\hline 3 & Polyanilline (PANI) & 15,000 & Soluble & 88.99 & BDH
\end{tabular}

Nanoparticles of $\mathrm{Au}$ and $\mathrm{Ag}$ were synthesized by the same protocol. $5 \mathrm{~mL} \mathrm{AgNO}_{3}$ $(1 \mathrm{mM})$ was mixed with $3 \mathrm{~mL}$ PANI $(1 \mathrm{mM})$ with constant stirring, and the mixture was heated at $55^{\circ} \mathrm{C}$ for 20 minutes. UV-Visible spectra were taken for confirmation of Ag nanoparticles. For the synthesis of $\mathrm{Au}$ nanoparticles, $5 \mathrm{~mL}$ of $\mathrm{AuCl}_{3}(1 \mathrm{mM})$ was heated at $70{ }^{\circ} \mathrm{C}$ for 25 minutes, and to a hot solution, $3 \mathrm{~mL}$ of PANI (1mM) was added. UV-Visible spectra were recorded, which gave a single peak and confirmed the formation of Au nanoparticles. Their $\lambda_{\max }$ values were at 420 and $455 \mathrm{~nm}$ for $\mathrm{Ag}$ and $\mathrm{Au}$, respectively, showing closeness to their reported values $(410 \mathrm{~nm}$ and $480 \mathrm{~nm})$ [21, 22]. These monometallic nanoparticles were synthesized to compare and confirm $\mathrm{Au}-\mathrm{Ag}$ bimetallic alloy (BMANPs) synthesized with various UV-Visible spectroscopy ratios. The details of experimental conditions required for the synthetic process are shown in Table 2 .

Table 2. Experimental conditions are required for the preparation of the various composition of Au-Ag alloy

\begin{tabular}{l|c|c|c|c|c} 
S. No & $\begin{array}{c}\text { Composition } \\
\mathbf{A u}-\mathbf{A g}\end{array}$ & $\begin{array}{c}\text { Volume of } \\
\mathbf{A g N O} \mathbf{3} / \mathbf{m L}\end{array}$ & $\begin{array}{c}\text { nolume of } \\
\mathbf{A u C l} \mathbf{3} \mathbf{m L}\end{array}$ & PANI/mL & $\mathbf{1 7 5}^{\mathbf{}} \mathbf{C} / \mathbf{m i n}$ \\
\hline 1 & $3: 1$ & 6 & 2 & 4 & 30 \\
\hline 2 & $2: 1$ & 4 & 2 & 3 & 20 \\
\hline 3 & $1: 1$ & 3 & 3 & 3 & 20 \\
\hline 4 & $1: 2$ & 2 & 4 & 3 & 20 \\
\hline 5 & $1: 3$ & 2 & 6 & 4 & 30
\end{tabular}


Similarly, Au-Ag alloy nanoparticles were synthesized by adding $5 \mathrm{~mL}$ of $\mathrm{AuCl}_{3}$ solution $(1 \mathrm{mM})$ to the mixture of $5 \mathrm{~mL} \mathrm{AgNO}_{3}$ solution $(1 \mathrm{mM})$ and $5 \mathrm{~mL}$ of PANI $(1 \mathrm{mM})$. The colloidal mixture was heated at a constant temperature of $175{ }^{\circ} \mathrm{C}$ for half an hour. The reaction started when the color of the solution turned black. The color was then changed to golden brown within a half-hour, showing the formation of bimetallic nanoparticles. The UVVisible spectrum of the colloidal mixture was taken, which has shown a single peak at 450, confirming Au-Ag bimetallic nanoparticles' formation composition of 1:1 [21-23].

Various samples of $\mathrm{Au}-\mathrm{Ag}$ BMANPs were synthesized using the same procedure. For such purpose, the amount of $\mathrm{AgNO}_{3}$ was changing, while the amount of $\mathrm{AuCl}_{3}$ was kept the same. The amount of PANI added was half of the total volume of each sample. All the samples, when dried were washed much time with acetone for complete removal of PANI. They were further dried by keeping in the drying oven at $50^{\circ} \mathrm{C}$ for 72 hours before analysis by XRD, EDS, and SEM [24].

\subsection{Instruments.}

For determination of $\lambda_{\max }$, molar attenuation coefficient $(\varepsilon)$, and confirmation of the formation of Au-Ag alloy nanoparticles, a UV-Visible Spectrophotometer (Shimadzu model 1601) was used. The emission spectra were recorded using a steady-state fluorescence spectrometer (Perkin Elmer LS 55). XRD was applied for crystallite size calculation of nanoparticles, and EDS was used for confirming the atomic composition of Au-Ag alloy nanoparticles. For the examination of the surface morphology of the nanoparticles, SEM was used [25].

\section{Results and Discussion}

Different compositions of bimetallic Au-Ag alloy nanoparticles were synthesized. Monometallic nanoparticles of $\mathrm{Au}$ and $\mathrm{Ag}$ nanoparticles were also synthesized for reference.

\subsection{UV-Visible spectroscopy.}

\subsection{1. effect of composition on $\lambda_{\max }$.}

Figure 1 shows UV-Visible spectra of monometallic nanoparticles of $\mathrm{Ag}, \mathrm{Au}$, and bimetallic Au-Ag alloy nanoparticles. Clearly, pure Ag and $\mathrm{Au}$ have shown different $\lambda_{\max }$ values when compared to their alloys. Ag and Au nanoparticles have shown a plasmon band maximum at $440 \mathrm{~nm}$ and $495 \mathrm{~nm}$, respectively, while the plasmon band maximum for $\mathrm{Au}-\mathrm{Ag}$ alloy is appearing at $450 \mathrm{~nm}$ accompanied by a raised base-line, indicating a possibility of aggregation and a resulting increase in the sizes of the synthesized alloy nanoparticles.

Figure 2 shows UV-Visible spectra of $\mathrm{Au}-\mathrm{Ag}$ alloy nanoparticles having various $\mathrm{Au}$ and $\mathrm{Ag}$ compositionsnd confirmed the alloy nanoparticles' formations. $\mathrm{Au}-\mathrm{Ag}(1: 1)$ gives $\lambda_{\text {max. }}$. at $450 \mathrm{~nm}, \mathrm{Au}-\mathrm{Ag}(1: 2)$ gives $\lambda_{\max }$ at $455 \mathrm{~nm}$, and $\mathrm{Au}-\mathrm{Ag}(1: 3)$ gives $\lambda_{\max }$ at $460 \mathrm{~nm}$. Alloy formation is further verified by the range of maximum wavelengths, that is, at the mid of pure $\mathrm{Ag}$ and Au nanoparticles. With the increase in Ag's composition in Au-Ag alloy nanoparticles, $\lambda_{\max }$ is shifting towards a lower wavelength which is useful to find the ratio at which the maximum absorptions can be achieved [26]. 


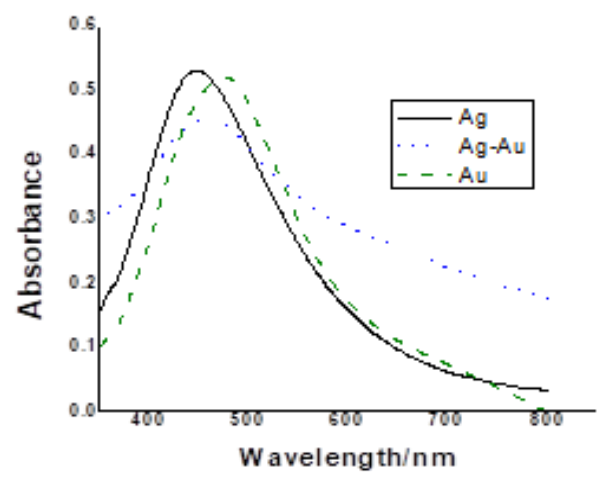

Figure 1. UV-Visible spectra of (1mM) Ag, $\mathrm{Au}$, and Ag-Au nanoparticles showing the formation of $\mathrm{Ag}-\mathrm{Au}$ alloy nanoparticles (using ethylene glycol as a solvent).

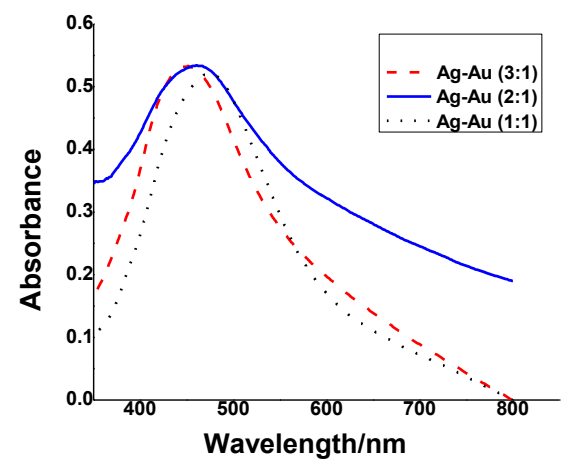

Figure 2. UV-Visible spectra of (1mM) Ag-Au (3:1) Ag-Au (2:1) Ag-Au (1:1) nanoparticles are showing bathochromic shift with an increase in the composition of Au in Ag-Au alloy nanoparticles.

The data obtained for $\lambda_{\max }$ is tabulated in Table 3 . The molar extinction coefficient is changing with the variation in the alloy's composition due to the change in the proportion of individual metal. Applying Beer-Lambert law, the molar absorptivity coefficient ' $\varepsilon$ ' was calculated from the slope of tabsorption versus concentration plot (Figures S1-S5 of supplementary data). The mathematical form of Beer-Lambert law is:

$$
\mathrm{A}=\varepsilon \mathrm{cl}
$$

Where in equation (1), $\mathrm{A}$ is absorbance, $\varepsilon$ is molar absorption coefficient in $\mathrm{M}^{-1} \mathrm{~cm}^{-1}$, $\mathrm{c}$ is concentration, while 1 is the path length. The peak due to the surface plasmon resonanceappears in the visible region [27]. As stated earlier, increase in Ag proportion showed a regular increase in absorbance and a shift in $\lambda_{\max }$ towards lower values, and hence at 1:3, Au-Ag alloy nanoparticles show maximum values of absorbance and $\varepsilon$, as given in Table 3 , which might be caused by the change in the index of refraction of the medium.

Table 3. UV-Vis spectral characteristics of Au-Ag alloy nanoparticles in different ratios.

\begin{tabular}{l|c|c|c|c|c|c} 
S. No & $\mathbf{A u}: \mathbf{A g}$ & $\mathbf{X}$ of Au & $\mathbf{X}$ of Ag & Absorbance & $\mathbf{8} / \mathbf{M}^{-1} \mathbf{c m}^{-\mathbf{1}}$ & $\boldsymbol{\lambda} \mathbf{m a x} / \mathbf{n m}$ \\
\hline 1 & $3: 1$ & 0.75 & 0.25 & 0.84 & 70.05 & 460 \\
\hline 2 & $2: 1$ & 0.66 & 0.33 & 0.85 & 75.05 & 455 \\
\hline 3 & $1: 1$ & 0.5 & 0.5 & 0.87 & 80.50 & 450 \\
\hline 4 & $1: 2$ & 0.33 & 0.66 & 0.88 & 84.85 & 448 \\
\hline 5 & $1: 3$ & 0.25 & 0.75 & 1.00 & 88.05 & 445
\end{tabular}

3.2. Variations in the mole fractions of $A u$ and $A g$ with changes in $\lambda_{\max }$.

Figure 3 shows that the trend in increasing wavelength of maximum $\left(\lambda_{\max }\right)$ was observed when the mole fraction of $\mathrm{Au}$ in $\mathrm{Au}-\mathrm{Ag}$ alloy nanoparticles was increased. It is clear 
that $\lambda_{\max }$ appeared at $440 \mathrm{~nm}$ for pure $\mathrm{Ag}$ and $\lambda_{\max }$ appeared at $495 \mathrm{~nm}$, represent the pure form of $\mathrm{Au}$, while the $\lambda_{\max }$ at the middle points showed $\mathrm{Ag}$-Au of various composition [28].

\subsection{Fluorescence spectroscopic studies.}

In this article, Au-Ag alloy nanoparticles' light emission behavior has been studied compared with $\mathrm{Au}$ and $\mathrm{Ag}$ nanoparticles. Au-Ag alloy nanoparticles give a single dominant emission peak at $575 \mathrm{~nm}$, as depicted in Figure 3. The fluorescence in Ag and Au nanoparticles have origin from the excitation of electrons from lower $\mathrm{d}$ orbital to sp-band of the excited electron and then coming back to the lowest band orbital by emission energy in the form of emission spectra [29]. The excitation wavelengths for $\mathrm{Ag}, \mathrm{Au}$, and $\mathrm{Au}-\mathrm{Ag}$ nanoparticles have been decided based on the Surface Plasmon Resonance absorption peaks. The Au-Ag alloy nanoparticles were excited at $450 \mathrm{~nm}$, while the $\mathrm{Ag}$ and $\mathrm{Au}$ nanoparticles have been excited at $440 \mathrm{~nm}$ and $495 \mathrm{~nm}$, respectively, as shown in Table 3. It has been reported that variation in the alloy composition by changing either Au or Ag causes a shift the alloy's $\lambda$ max emission, which can be attributed to the change in the size of the alloy nanoparticles [30]. Our results confirm that the formation of $\mathrm{Au}, \mathrm{Ag}$, and $\mathrm{Au}-\mathrm{Ag}$ alloy nanoparticles by comparing the absorption and emission peaks' position and intensities. By increasing Ag's relative concentration, the quenching action of Ag appeared, and fluorescence intensity was reduced and caused a shift to shorter wavelengths, as shown in Figure 3.

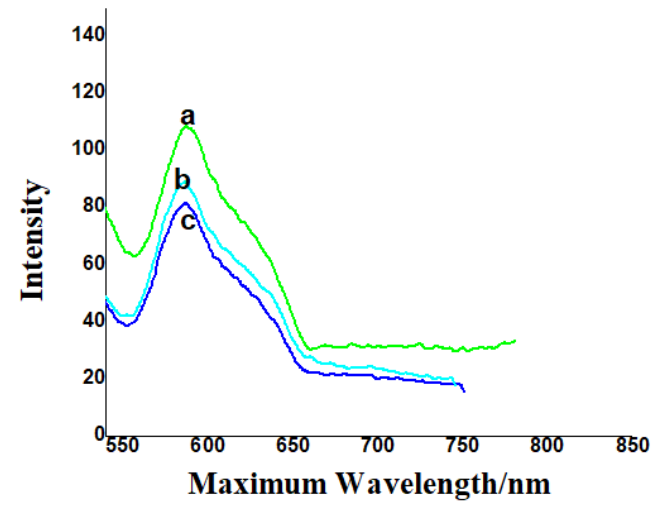

Figure 3. Emission spectra Ag-Au alloy in which mole fraction of Ag is 0.5 (a), 0.75(b), and 0.9 (c) nanoparticles with varying $\mathrm{Ag}$ mole fraction.

The quenching action of $\mathrm{Ag}$ in the overall composition can be quantified using the following set of equations:

$$
\log \frac{I_{0}}{I_{Q}}=\frac{[Q] N}{[x]}
$$

In the equation above, $\mathrm{I}_{0}$ is the fluorescence intensity of the alloy nanoparticles suspension initially, and $\mathrm{I}_{\mathrm{Q}}$ indicates the intensity of alloy nanoparticles while increasing the proportion of $\mathrm{Ag}$ in the $\mathrm{Au}-\mathrm{Ag}$ alloy nanoparticles and then making the suspension. Here [Q] shows the relative proportion of $\mathrm{Ag}$ as quencher concentration, and $[\mathrm{X}]$ is alloy concentration in millimolar $(\mathrm{mM}) . \mathrm{N}$ is the number of atoms in alloy nanoparticles.

The binding constant $\mathrm{kb}_{\mathrm{b}}$ and the number of sites (n) provided for binding by one nanoparticle to another can be calculated using the relation

$$
\log \frac{I_{0}-I_{Q}}{I_{Q}}=\log k_{b}+\mathrm{n} \log [\mathrm{Q}]
$$


It was noted that the number of binding sites $\mathrm{n}$ and binding constant $\mathrm{kb}$ steadily decrease with the decrease in the relative proportion of $\mathrm{Au}$ in the overall composition of Au-Ag alloy, as shown in Table 3. Free energy of binding $(\Delta \mathrm{Gb})$ can be calculated using Eq. (4) below

$$
\Delta G_{b}=\mathrm{RT} \ln k_{b}
$$

Where $\mathrm{R}$ is the universal gas constant having the value $8.3144 \mathrm{JK}^{-1} \mathrm{~mol}^{-1}, \mathrm{~T}$ is the temperature expressed in the Kelvin scale, and $\mathrm{kb}$ is the binding constant. Increasing the Ag ratio in the composition of $\mathrm{Au}-\mathrm{Ag}$ alloy shows a hypochromic effect. The similarity in the fluorescence profiles of $\mathrm{Au}-\mathrm{Ag}$ 3:1 to $\mathrm{Au}-\mathrm{Ag} 1: 1$ and $\mathrm{Au}-\mathrm{Ag}$ 1:1 to $\mathrm{Au}-\mathrm{Ag}$ 1:3 in terms of their intensities and wavelength of emission indicates the similarities in their crystal structures.

Table 4. Various parameters were obtained from fluorescence spectroscopy of Au-Ag alloy nanoparticles with

\begin{tabular}{|c|c|c|c|c|c|c|}
\hline S. No & $\begin{array}{c}\text { Sample } \\
\text { Au-Ag }\end{array}$ & $\mathbf{I}_{0}$ & $\lambda_{\max } / \mathbf{n m}$ & Binding site (n) & $\begin{array}{c}\text { Binding constant } \\
(\mathbf{k b})\end{array}$ & $\Delta \mathrm{G}_{\mathrm{b}} \mathrm{KJ} / \mathrm{mol}$ \\
\hline 3 & $1: 1$ & 300 & 590 & 0.41 & 15.50 & -15.55 \\
\hline 4 & $1: 2$ & 300 & 580 & 0.32 & 09.85 & -18.50 \\
\hline 5 & $1: 3$ & 300 & 575 & 0.22 & 05.05 & -20.25 \\
\hline
\end{tabular}

Table 4 shows that fluorescence intensity decrease with an increase in the composition of $\mathrm{Ag}$. The highest intensity is observed for $\mathrm{Au}-\mathrm{Ag}$ 1:1 due to the lower composition of $\mathrm{Ag}$ in it, while the lowest intensity is observed for $\mathrm{Au}-\mathrm{Ag}$ 1:3 that has a maximum composition of $\mathrm{Ag}$. There is a regular decline in $\lambda_{\max }$ with an increase in the composition of $\mathrm{Ag}$. The binding sites $(\mathrm{n})$, binding constant $\left(\mathrm{k}_{\mathrm{b}}\right)$, and free energy of binding $\left(\Delta \mathrm{G}_{\mathrm{b}}\right)$ increase regularly with an increase in the composition of $\mathrm{Ag}$. The regular increasing trend in $\Delta \mathrm{Gb}$ (with negative value), indicates that the process gets more spontaneity as Ag's composition is raised.

\subsection{X-Ray diffraction analysis (XRD).}

X-ray diffraction analysis was carried out to confirm the phase purity of synthesized samples, and the resulting diffraction pattern is shown in Figure 4. It is clearly shown by Fig. 4 that all samples exhibit mostly peaks comparable to that of the standard patterns, namely 00001-1167 and 00-004-0784. However, the sample with an Au-Ag ratio of 1:3, 2:1, and 1:3 show less intense impurity peaks at a $2 \theta$ value of 35 , representing the possibility for the formation of $\mathrm{Ag}_{2} \mathrm{O}$ during the synthesis. The X-ray diffraction occurs mainly at lattice planes of (101), (210), and (220) with the first peak of maximum intensity at 35, 42, and 68 positions, respectively [31]. The crystallite sizes were calculated from the full width at half maximum of the most intense peak (101) using the following Sharer's formula;

$$
D=\frac{k \lambda}{\beta \cos \theta}
$$

Where $\mathrm{k}$ is the shape factor with a value of $0.9, \lambda$ is the wavelength of $\mathrm{CuK} \alpha$ radiations $(1.54 \mathrm{~A})$, $\beta$ is the full width at half the maximum of the diffraction and obtained using Gaussian fit the corresponding peak with maximum intensity.

The calculated crystallite sizes are given in Table 5, showing that the smallest crystallite size was found for a sample with an Ag to Au ratio of 1:3. The lattice parameters ' $a$ ' for the samples are calculated using the equation,

$$
a=\sqrt{d^{2}\left(h^{2}+k^{2}+l^{2}\right.}
$$


Where, $\mathrm{d}$ is the interspacing of planes in the crystal structure, responsible for the diffraction lines in the XRD pattern, while $\mathrm{h}, \mathrm{k}$, and 1 are the Miller indices. The values for the lattice parameters and the cell volumes for all the synthesized samples are given in Table 5.

Table 5. Sizes of Ag-Au (in various ratios with $\mathrm{Au}-\mathrm{Ag}$ 1:3 having the smallest size), Ag and Au nanoparticles.

\begin{tabular}{l|c|c|c|c} 
S No. & $\begin{array}{c}\text { Bimetallic } \\
\text { Au-Ag }\end{array}$ & Size nm & Monometallic & Size nm \\
\hline 1 & $3: 1$ & 35 & \multirow{2}{*}{$\mathrm{Au}$} & \\
\hline 2 & $2: 1$ & 33 & & \\
\hline 3 & $1: 1$ & 30 & $\mathrm{Ag}$ & 35 \\
\hline 4 & $1: 2$ & 27 & &
\end{tabular}

The variations in the lattice parameters pointing that the mechanism for the formation of $\mathrm{Au}-\mathrm{Ag}$ alloys is somehow complex apart from some impurity peaks observed for $\mathrm{Ag}_{2} \mathrm{O}$. However, the variation in the lattice parameter and corresponding cell volume can be attributed to the difference in the sizes for the atomic radii of $\mathrm{Ag}(1.75 \mathrm{~A})$ and $\mathrm{Au}(1.79 \mathrm{~A})$. In the first sample with an Ag to Au ratio of 1:1, the value of the lattice constant is comparable to that of a standard pattern (4.08 A). Further increase in the Ag content changes the lattice parameter with maximum value for $\mathrm{Au}-\mathrm{Ag}$ ratio of 1:3 [32]. Beyond this ratio, the lattice constant and the cell volume decrease as the Ag content with comparably lower atomic radius increases in the samples, confirming the size-size-dependent differences in the lattice constant and cell volume.

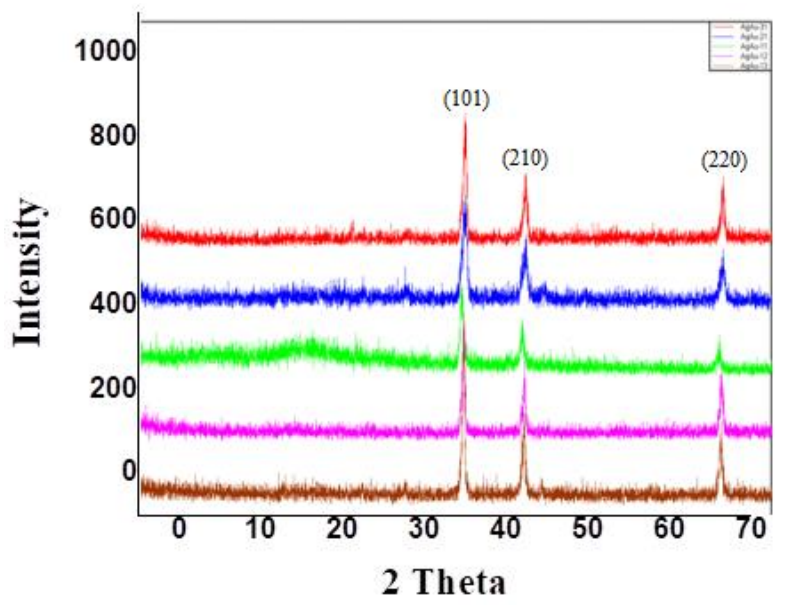

Figure 4. XRD patterns of of Ag-Au 3:1, Ag-Au 2:1, Ag-Au 1:1, Ag-Au 1:2, Ag, and Ag-Au 1:3.

\subsection{EDS studies.}

Energy dispersive spectroscopy (EDS) shows the various compositions of $\mathrm{Ag}$ and $\mathrm{Au}$ in Ag-Au alloy NPs (Figures 5). Ag-Au at the ratio of $3: 1$ shows clearer composition (Figure 5-A). EDS shows the elemental composition of Ag and $\mathrm{Au}$ in $\mathrm{Ag}-\mathrm{Au}$ alloy nanoparticles with various compositions.

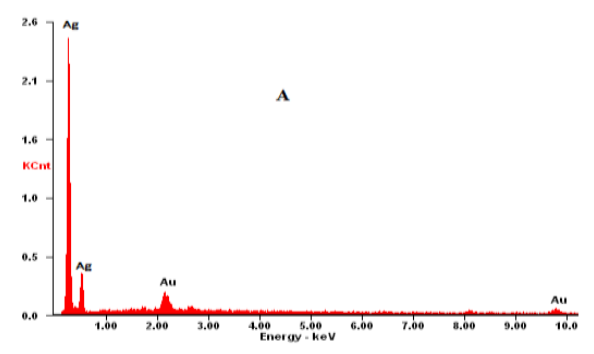



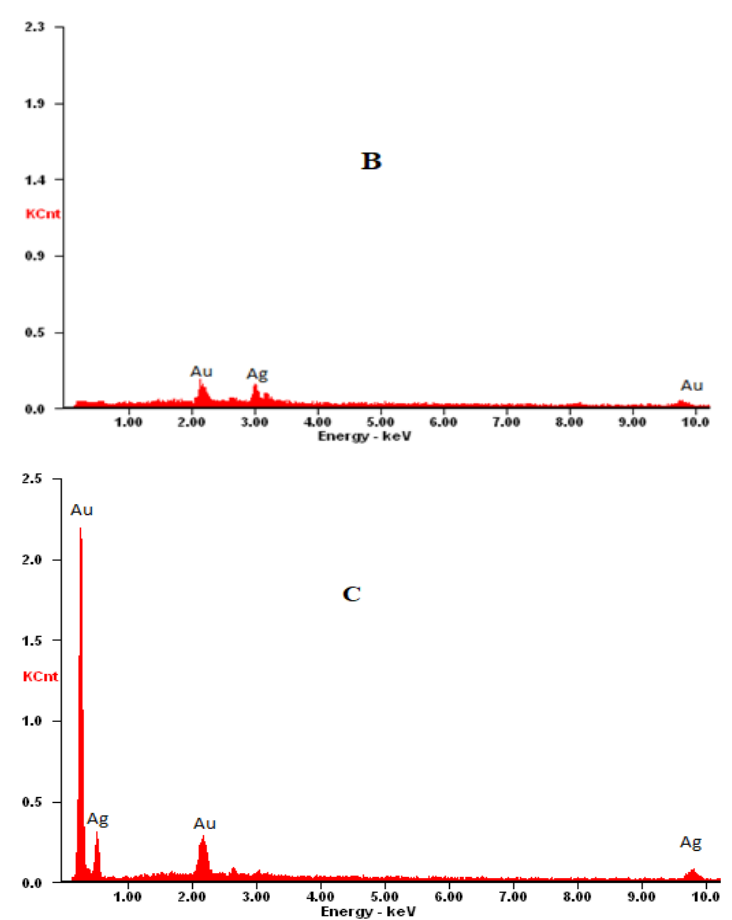

Figure 5. EDS for Ag-Au (3:1), Ag-Au (1:1) and Ag-Au (1:3).

\subsection{SEM studies.}

The morphological structures of Ag NPs, Au NPs, and Ag-Au alloy NPs, prepared with various ratios, are shown in Figures 6 and 7. The as-prepared Au-Ag 1:3 alloy NPs have an average diameter of $25 \pm 2 \mathrm{~nm}$ (Figure 5E), which is smaller than that of $38 \pm 2 \mathrm{~nm}$ and $45 \pm 2 \mathrm{~nm}$ for the Ag NPs and Au NPs, respectively (Figure 6 and Figure 7).
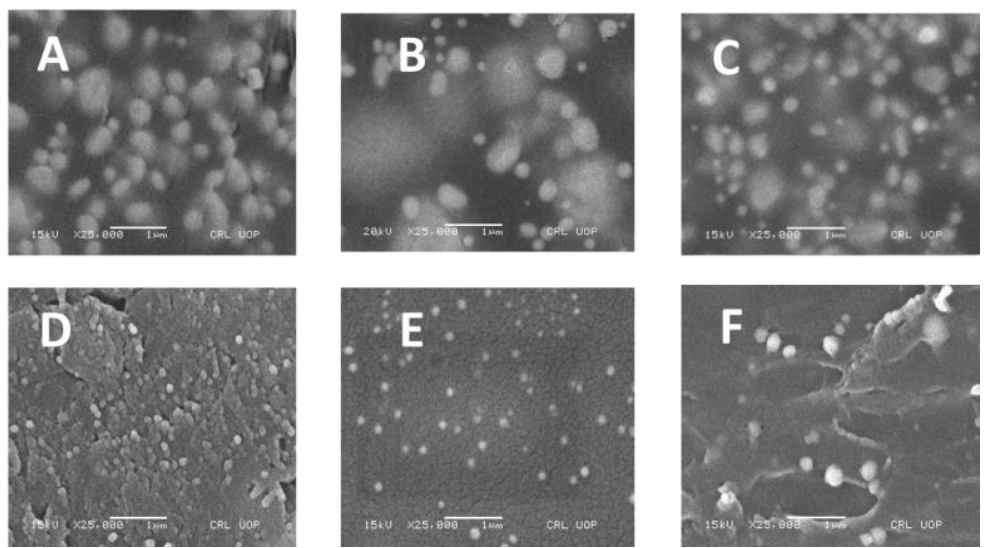

Figure 6. SEM Images of Au-Ag 3:1 (A), Au-Ag 2:1 (B), Au-Ag 1:1 (C), Au-Ag 1:2 (D), Au-Ag 1:3 (E), AuAg 1:4 (F) Showing the smallest and uniform size of Ag-Au bimetallic alloy nanoparticles at a ratio of 1:3.
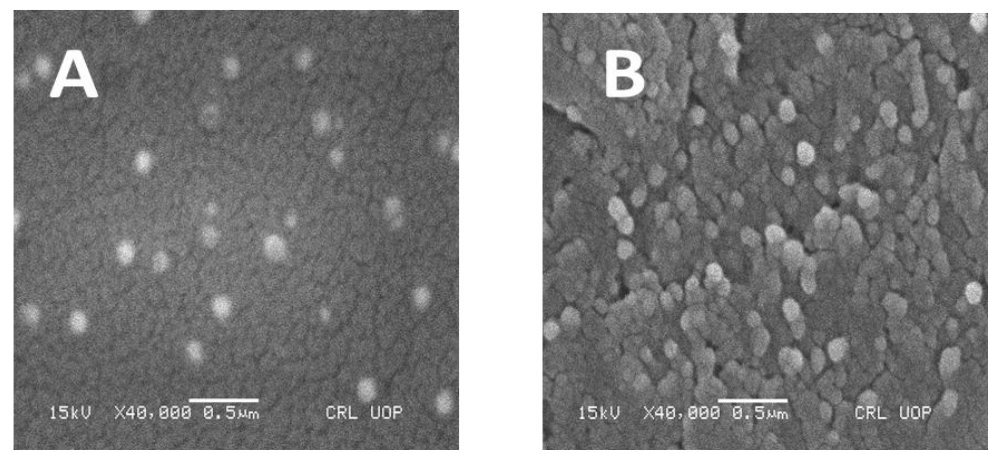

Figure 7. SEM Images of Ag (A) and Au (B) NPs. 
In general, the SEM micrographs a uniform surface morphology that supports the data obtained from XRD. The lattice spacing obtained mismatch was observed since the Au and Ag have very similar lattice parameters. SEM micrographs show the agglomeration tendency of alloy nanoparticles among themselves. The reason could be the high surface energy of these particles due to their nano-size regime. This supports the data obtained from UV-Visible spectroscopy for the alloy nanoparticles in solution (Figures. 1 and 2), where we observed an elevation in the base-line with the formation of alloy nanoparticles [33]. The average size of Au-Ag bimetallic alloy nanoparticles ranges from $35 \mathrm{~nm}$ to $25 \mathrm{~nm}$, as shown in Table 5 . Interestingly size of bimetallic alloy nanoparticles decreases as thecomposition of $\mathrm{Ag}$ in $\mathrm{Au}-$ Ag nanoparticles increases.

\section{Conclusions}

BMANPs of $\mathrm{Au}$ and Ag of various compositions were successfully synthesized by the chemical reduction method. The as-prepared alloys' spectroscopic datawere compared with Pure Ag and Au NPs, which were prepared as reference materials. The synthesis of NPs was monitored by UV/visible spectroscopy and was characterized by Fluorescence, EDS, XRD, and SEM techniques. The effect of composition on $\lambda_{\max }$ and $\varepsilon$ was also examined, and their trends were studied. Fluorescence spectroscopic studies reveal that Ag is acting as a quencher for the emission radiation in Au-Ag alloy NPs. Fluorescence tabulated data shows that the binding site $(\mathrm{n})$ and binding constant $(\mathrm{kb})$ decreases with increasing Ag's composition in $\mathrm{Au}-$ Ag alloy NPs. Fluorescence also reflects the spontaneity of the process $(\Delta \mathrm{G})$. XRD was used for the calculation of average diameters of nanoparticles and study of crystal lattice composition as well as for surface morphology. SEM also showed the morphology and size of alloy NPs. SEM images of the synthesized NPs reveal that Ag-Au 1:3 has the smallest size 25 $\mathrm{nm}$, and shows a high value of $\varepsilon$ due to their closed compatibility. Hence it is concluded that NPs of Au-Ag with a ratio of 1:3 is expected to optimize the sensing power of nanoparticlebased electrochemical sensors for monitoring of the worst environmental toxins, PAHs, and carcinogenic volatile organic compounds (VOCs).

\section{Funding}

This research received no external funding.

\section{Acknowledgments}

This work was jointly supported by the Institute of the Chemical Sciences University of Peshawar, Chemistry Department of Quaid-i-Azam University, Islamabad, and Higher Education Commission of Pakistan.

\section{Conflicts of Interest}

The authors declare no conflict of interest.

\section{References}

1. Rahman, L.-u.; Shah, A.; Han, C.; Khaliq, A. Monitoring of Anthracene Using Nanoscale Au-Cu Bimetallic Alloy Nanoparticles Synthesized with Various Compositions. ACS Omega 2020, 5, 22494-22501, https://doi.org/10.1021/acsomega.0c03104. 
2. Roy, D.; Pal, T. Nanostage Alloying of Metals in Liquid Phase. Advances in Chemical Engineering and Science 2021, 11, 105-140, https://doi.org/10.4236/aces.2021.111008.

3. Kehoe, D.K.; McCarthy, S.A.; Romeral, L.; Lyons, M.G.; Gun'ko, Y.K. Pt and RhPt dendritic nanowires and their potential application as anodic catalysts for fuel cells. RSC Advances 2019, 9, 31169-31176, https://doi.org/10.1039/C9RA04801D.

4. Shah, A.; Rahman, L.-u.; Qureshi, R.; Rehman, Z.-u. Synthesis, characterization and applications of bimetallic ( $\mathrm{Au}-\mathrm{Ag}, \mathrm{Au}-\mathrm{Pt}, \mathrm{Au}-\mathrm{Ru}$ ) alloy nanoparticles. Reviews on advanced materials science 2012, 30, 133-149.

5. Zaka, M.; Abbasi, B.H.; Rahman, L.U.; Shah, A.; Zia, M. Synthesis and characterisation of metal nanoparticles and their effects on seed germination and seedling growth in commercially important Eruca sativa. IET nanobiotechnology 2016, 10, 134-140, https://doi.org/10.1049/iet-nbt.2015.0039.

6. Li, X.; Gui, L.; Zou, H. Bracelet-Like Ni0.4Cu0.6O Microstructure Composed of Well-Aligned Nanoplatelets as a Superior Catalyst to the Hydrolysis of Ammonia Borane. Front Chem 2019, 7.

7. Rahman, L.-U.; Shah, A.; Qureshi, R.; Khan, S.; Asiri, A.M.; Shah, A.-u.-H.; Ishaq, M.; Khan, M.; Lunsford, S.; Zia, M. Spectroscopic Analysis of Au-Cu Alloy Nanoparticles of Various Compositions Synthesized by a Chemical Reduction Method. Advances in Materials Science and Engineering 2015, 2015, https://doi.org/10.1155/2015/638629.

8. Rahman, L.-U.; Shah, A.; Lunsford, S.K.; Han, C.; Nadagouda, M.N.; Sahle-Demessie, E.; Qureshi, R.; Khan, M.S.; Kraatz, H.-B.; Dionysiou, D.D. Monitoring of 2-butanone using a Ag-Cu bimetallic alloy nanoscale electrochemical sensor. RSC Advances 2015, 5, 44427-44434, https://doi.org/10.1039/C5RA03633J.

9. Latif ur, R.; Shah, A.; Khan, S.B.; Asiri, A.M.; Hussain, H.; Han, C.; Qureshi, R.; Ashiq, M.N.; Zia, M.A.; Ishaq, M.; Kraatz, H.-B. Synthesis, characterization, and application of $\mathrm{Au}-\mathrm{Ag}$ alloy nanoparticles for the sensing of an environmental toxin, pyrene. Journal of Applied Electrochemistry 2015, 45, 463-472, https://doi.org/10.1007/s10800-015-0807-2.

10. Salman Khan, M.; Zaka, M.; Haider Abbasi, B.; Rahman, L.; Shah, A. Seed germination and biochemical profile of Silybum marianum exposed to monometallic and bimetallic alloy nanoparticles. IET nanobiotechnology 2016, 10, 359-366, https://doi.org/10.1049/iet-nbt.2015.0050.

11. Olszewski, T.K.; Adler, P.; Grison, C. Bio-based Catalysts from Biomass Issued after Decontamination of Effluents Rich in Copper-An Innovative Approach towards Greener Copper-based Catalysis. Catalysts 2019, 9, https://doi.org/10.3390/catal9030214.

12. Hong, Y.; Peng, J.; Sun, Z.; Yu, Z.; Wang, A.; Wang, Y.; Liu, Y.-Y.; Xu, F.; Sun, L.-X. Transition Metal Oxodiperoxo Complex Modified Metal-Organic Frameworks as Catalysts for the Selective Oxidation of Cyclohexane. Materials 2020, 13, 820-829, https://doi.org/10.3390/ma13040829.

13. Khan, M.; Al-Hamoud, K.; Liaqat, Z.; Shaik, M.R.; Adil, S.F.; Kuniyil, M.; Alkhathlan, H.Z.; Al-Warthan, A.; Siddiqui, M.R.H.; Mondeshki, M.; Tremel, W.; Khan, M.; Tahir, M.N. Synthesis of Au, Ag, and Au-Ag Bimetallic Nanoparticles Using Pulicaria undulata Extract and Their Catalytic Activity for the reduction of 4-Nitrophenol. Nanomaterials (Basel) 2020, 10, 1879-1885, https://doi.org/10.3390/nano10091885.

14. Sankar, M.; He, Q.; Engel, R.V.; Sainna, M.A.; Logsdail, A.J.; Roldan, A.; Willock, D.J.; Agarwal, N.; Kiely, C.J.; Hutchings, G.J. Role of the Support in Gold-Containing Nanoparticles as Heterogeneous Catalysts. Chemical Reviews 2020, 120, 3890-3938, https://doi.org/10.1021/acs.chemrev.9b00662.

15. Majeed, S.A.; Sekhosana, K.E.; Tuhl, A. Progress on phthalocyanine-conjugated Ag and Au nanoparticles: Synthesis, characterization, and photo-physicochemical properties. Arabian Journal of Chemistry 2020, 13, 8848-8887, https://doi.org/10.1016/j.arabjc.2020.10.014.

16. Munir, M.; Ahmad, M.; Saeed, M.; Waseem, A.; Rehan, M.; Nizami, A.-S.; Zafar, M.; Arshad, M.; Sultana, S. Sustainable production of bioenergy from novel non-edible seed oil (Prunus cerasoides) using bimetallic impregnated montmorillonite clay catalyst. Renewable and Sustainable Energy Reviews 2019, 109, 321-332, https://doi.org/10.1016/j.rser.2019.04.029.

17. Sun, R.; Wang, J.; Peng, Y.; Wang, H.; Chen, Q. Mitigation of arsenic accumulation in arugula (Eruca sativa Mill.) using Fe/Al/Zn impregnated biochar composites. Environmental Science and Pollution Research 2021, 28, 4136-4146, https://doi.org/10.1007/s11356-020-10476-X.

18. Hussain, M.; Raja, N.; Mashwani, Z.-u.-R.; Iqbal, M.; Ejaz, M.; Yasmeen, F.; Sohail. In Vitro Germination and Biochemical Profiling of Citrus reticulata in Response to Green Synthesized Zinc and Copper Nanoparticles. IET nanobiotechnology 2017, 11, 790-796, https://doi.org/10.1049/iet-nbt.2016.0256.

19. Shiraishi, Y.; Sakamoto, H.; Sugano, Y.; Ichikawa, S.; Hirai, T. Pt-Cu Bimetallic Alloy Nanoparticles Supported on Anatase TiO2: Highly Active Catalysts for Aerobic Oxidation Driven by Visible Light. ACS Nano 2013, 7, 9287-9297, https://doi.org/10.1021/nn403954p.

20. Vasile, O.R.; Andronescu, E.; Truşcă, R.; Vasile, E.; Holban, A.M.; Chifiriuc, M.C.; Iordache, F.; Maniu, H.; Bleotu, C.; Neacşu, I.A.; Vasile, B. Structure-grain size-synthesis route of silver nanoparticles: a correlation with the cytotoxic effect. Rom J Morphol Embryol, , 2019, 60, 617-628, ISSN: 1220-0522, WOS:000493322700029. 
21. Mailu, S.N.; Waryo, T.T.; Ndangili, P.M.; Ngece, F.R.; Baleg, A.A.; Baker, P.G.; Iwuoha, E.I. Determination of anthracene on $\mathrm{Ag}$-Au alloy nanoparticles/overoxidized-polypyrrole composite modified glassy carbon electrodes. Sensors (Basel) 2010, 10, 9449-9465.

22. Malathi, S.; Ezhilarasu, T.; Abiraman, T.; Balasubramanian, S. One pot green synthesis of Ag, Au and AuAg alloy nanoparticles using isonicotinic acid hydrazide and starch. Carbohydrate Polymers 2014, 111, 734743, https://doi.org/10.1016/j.carbpol.2014.04.105.

23. Waag, F. Laser Synthesis of Metallic and Oxidic Transition Metal, Multi-Element Nanoparticles for Catalytic Applications. Doctoral dissertation, Universität Duisburg-Essen 2019, 10, 119-130.

24. Tunc, I.; Guvenc, H.O.; Sezen, H.; Suzer, S.; Correa-Duarte, M.A.; Liz-Marzán, L.M. Optical response of Ag-Au bimetallic nanoparticles to electron storage in aqueous medium. J Nanosci Nanotechnol 2008, 8, 3003-3007, https://doi.org/10.1166/jnn.2008.157.

25. Chowdhury, S.; Bhethanabotla, V.R.; Sen, R. Effect of Ag-Cu Alloy Nanoparticle Composition on Luminescence Enhancement/Quenching. The Journal of Physical Chemistry C 2009, 113, 13016-13022, https://doi.org/10.1021/jp900294z.

26. Luo, Q.; Lai, J.; Qiu, P.; Wang, X. An ultrasensitive fluorescent sensor for organophosphorus pesticides detection based on RB-Ag/Au bimetallic nanoparticles. Sensors and Actuators B: Chemical 2018, 263, 517523, https://doi.org/10.1016/j.snb.2018.02.101.

27. Robinson, I.K. Direct Determination of the Au(110) Reconstructed Surface by X-Ray Diffraction. Physical Review Letters 1983, 50, 1145-1148, https://doi.org/10.1103/PhysRevLett.50.1145.

28. Buss, C.E.; Anderson, C.E.; Pomije, M.K.; Lutz, C.M.; Britton, D.; Mann, K.R. Structural Investigations of Vapochromic Behavior. X-ray Single-Crystal and Powder Diffraction Studies of $[\mathrm{Pt}(\mathrm{CN}$-isoC3H7)4][M(CN)4] for M = Pt or Pd. Journal of the American Chemical Society 1998, 120, 7783-7790, https://doi.org/10.1021/ja981218c.

29. Srnová-Šloufová, I.; Lednický, F.; Gemperle, A.; Gemperlová, J. Core-Shell (Ag)Au Bimetallic Nanoparticles: Analysis of Transmission Electron Microscopy Images. Langmuir 2000, 16, 9928-9935, https://doi.org/10.1021/la0009588.

30. Priya, A.; Saminathan, S.; Balasundaram, J. Green synthesis of NiO nanoparticles using Leucas Aspera and its antibacterial activity. Letters in Applied NanoBioScience, 2020, 9, 1033-1036, https://doi.org/10.33263/LIANBS92.10331036.

31. Smith, A.T.; LaChance, A.M.; Zeng, S.; Liu, B.; Sun, L. Synthesis, properties, and applications of graphene oxide/reduced graphene oxide and their nanocomposites. Nano Materials Science 2019, 1, 31-47, https://doi.org/10.1016/j.nanoms.2019.02.004

32. Khosravi-Darani, K.; Gomes, A.; Cruz, M. R.; Zohreh, A.; Negin, M. Biosynthesis of metal nanoparticles by probiotic bacteria. Letters in Applied NanoBioScience 2019, 8, 619-626, https://doi.org/10.33263/LIANBS83.619626.

33. Xu, Z.; Zhang, H.; Liu, S.; Zhang, B.; Zhong, H.; Su, D.S. Facile synthesis of supported Pt-Cu nanoparticles with surface enriched Pt as highly active cathode catalyst for proton exchange membrane fuel cells. International Journal of Hydrogen Energy 2012, 37, 17978-17983, https://doi.org/10.1016/j.ijhydene.2012.09.050. 


\section{Supplementary materials}

Figure S1-S5 show UV-visible spectra of Au-Ag alloy NPs with different composition between $\mathrm{Au}$ and $\mathrm{Ag}$ synthesized by the chemical reduction method from $\mathrm{AuCl}_{3}$, $\mathrm{AgNO}_{3}$ in the presence of PANI as a capping agent. The figures show that with an increase in Au's composition in Au-Ag bimetallic alloy nanoparticles, the $\lambda_{\max }$ increases, and the lowest $\lambda_{\max }$ is observed for $\mathrm{Au}-\mathrm{Ag}$ with a ration 1:3, which shows the maximum value for molar attenuation value.

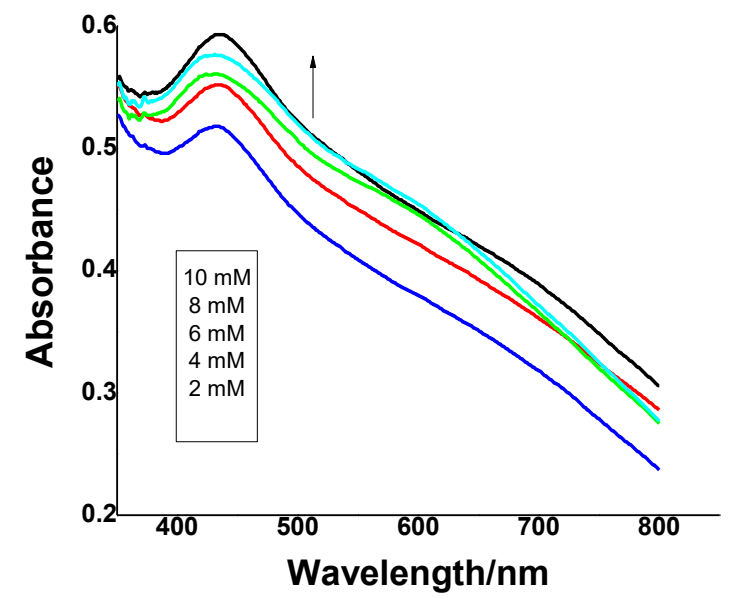

Figure S1. UV-Visible Spectra of Au-Ag 1:3 at $298 \mathrm{~K}$.

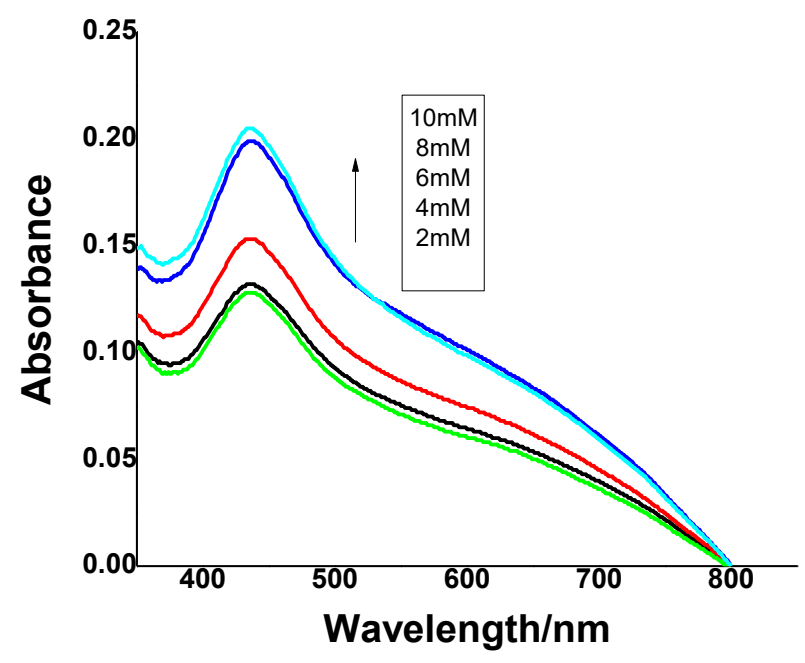

Figure S2. UV-Visible Spectra of Au-Ag 1:2 at $298 \mathrm{~K}$.

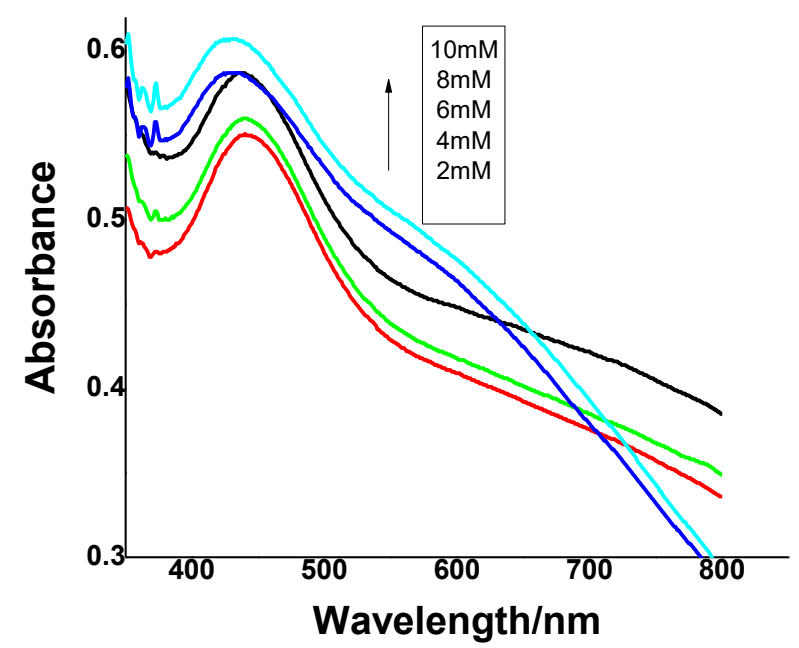

Figure S3. UV-Visible Spectra of Au-Ag 1:1 at $298 \mathrm{~K}$. 


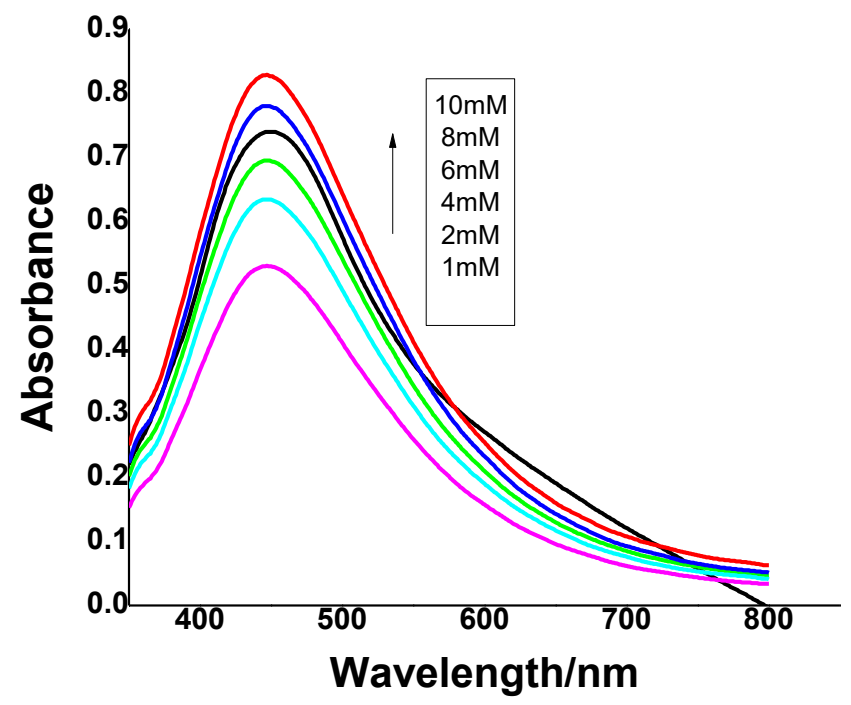

Figure S4. UV-Visible Spectra of Au-Ag 2:1 at $298 \mathrm{~K}$.

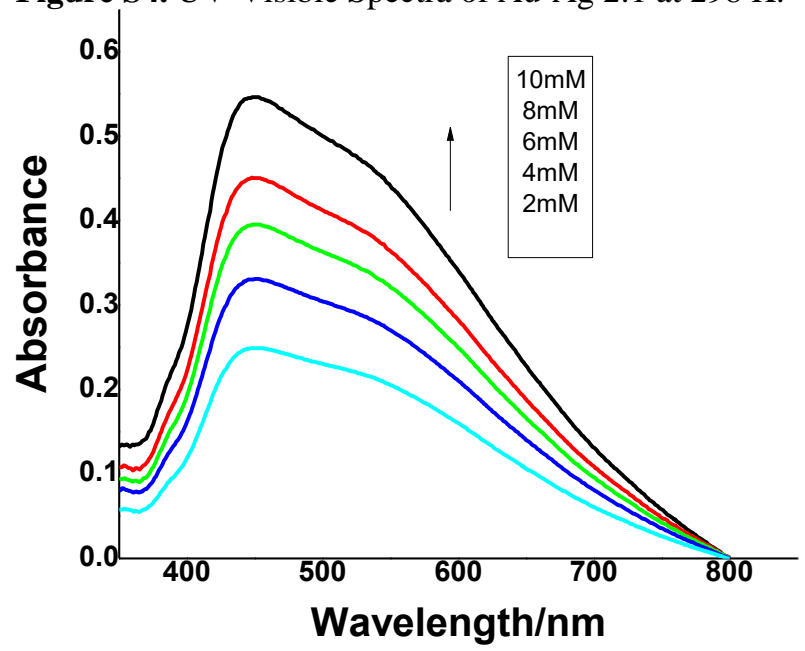

Figure S5. UV-Visible Spectra of Au-Ag 3:1 at $298 \mathrm{~K}$. 